\title{
Development of interspecific hybrids between Solanum lycopersicum L. and S. sisymbriifolium Lam. via embryo calli
}

\author{
Lukasz Piosik (i) - Maria Ruta-Piosik • Maciej Zenkteler • Elżbieta Zenkteler
}

Received: 18 April 2018/ Accepted: 21 January 2019/Published online: 28 January 2019

(C) The Author(s) 2019

\begin{abstract}
Solanum sisymbriifolium, a wild relative of the S. lycopersicum species, has been found to be resistant to numerous pathogens which cause severe diseases in Solanaceae crops. It would be highly desirable for species strongly affected by diseases (e.g. tomato) to contain the resistant genes found in their wild relatives. Solanum sisymbriifolium has been considered of potential interest for S. melongena $\mathrm{L}$. breeding, as the former is resistant to several pathogens and resistant interspecific hybrids have been obtained. Additionally, several reports indicate that $S$. sisymbriifolium is useful for tomato gynogenic haploid production. It is still not quite clear whether $S$. sisymbriifolium can be crossed with $S$. lycopersicum and the development of hybrid progeny is possible. In our preliminary in vivo crossing, $S$. lycopersicum $\times S$. sisymbriifolium diploid embryos were formed inside fruits, but their development was inhibited at the globular stage. To obtain F1 hybrids the embryorescue method was implemented. Globular embryos isolated 14-35 dap were cultured on various media showing varied morphogenic potencies. Most of the embryos did not develop on the used media but calli formed from the embryogenic cells in $>17 \%$ of the embryos, allowing hybrid plants to be obtained. Ten
\end{abstract}

Ł. Piosik $(\bowtie) \cdot$ M. Ruta-Piosik · M. Zenkteler •

E. Zenkteler

Department of General Botany, Faculty of Biology, Adam

Mickiewicz University, Poznan, Poland

e-mail: 1.piosik@amu.edu.pl regenerants, which were adapted in pots containing soil, had morphological traits similar to the $S$. sisymbriifolium parent, including the plant habit, presence of prickles on shoots or white colour of flowers. The hybrid origin of the regenerants was confirmed by flow cytometry analysis of DNA content and KASP genotyping. The results indicated that $S$. lycopersicum can be hybridized with $S$. sisymbriifolium through interspecific hybridization to introduce novel traits for use in tomato-breeding programmes.

Keywords Interspecific hybridization - Solanum lycopersicum $\times$ Solanum sisymbrifolium $\cdot$ Embryo rescue $\cdot$ Embryogenic callus

\section{Introduction}

Solanum lycopersicum L. $(2 \mathrm{n}=24)$, previously known as Lycopersicon esculentum Mill., originated in the Andean region and is in high demand around the world. The tomato belongs to the Solanaceae family, which contains about 3000 species (Knapp 2002). The genus Solanum contains around 1500 species and is the largest in the Solanaceae family. Many Solanum species are cultivated to provide economically important crops (Fawzi and Habeeb 2016), with the global tomato seed market being worth around 500 million 
euros (Bai and Lindhout 2007). The Lycopersicon section of the Solanum genus includes the cultivated tomato and 12 wild relatives, e.g. S. peruvianum L. and S. pimpinellifolium L. (Peralta et al. 2005). Cultivation for human consumption has led to the development of many different cultivars and forms of S. lycopersicum. Research and breeding activities by scientists and plant breeders have led to the creation of numerous varieties with fruits of different shapes, colors, and tastes. Tomato breeding is currently a vibrant industry, developing new and improved cultivars.

One of the most important issues in tomato breeding is resistance to pests and pathogens, of which there are around 200 species affecting tomatoes, causing considerable economic losses (Bai and Lindhout 2007). The tomato is highly prone to various nematodes, aphids and diseases such as bacterial, viral and fungal wilts, caused by multiple factors, recognized as the most severe of all threats to tomato cultivation. Fungal wilts are often caused by Fusarium oxysporum species which enter through the roots and colonize the vascular system, initially causing yellowing and wilting of leaves and shoots (Sikora and Gazaway 2009). Verticillium wilt, caused by the Verticillium dahliae fungus and other species, causes similar symptoms to Fusarium, and attacks tomato, eggplant, pepper, and potato plants (Alconero et al. 1988; Sikora and Gazaway 2009). Other severe threats to large-scale tomato and eggplant cultivation include bacterial wilt (Collonnier et al. 2003; Sikora and Gazaway 2009), caused by infections with the Ralstonia solanacearum species complex (Safni et al. 2014) which may also cause partial or complete wilting. Tomatoes are also affected by root-knot nematodes Meloidogyne spp., which affect more than 2000 other plant species (Sikora and Gazaway 2009).

The genes responsible for the resistance of tomato plants to pathogens are often available in wild tomato relatives. Cultivated tomatoes have much less genetic variety than wild tomatoes, for example plants belonging to the $S$. lycopersicum genome have less than $5 \%$ of the genetic variability of their wild relatives (Miller and Tanksley 1990). However, limited crossability often prevents these important genes being introduced into commercial cultivars. Breaking down interspecific barriers is therefore a very important aspect of tomato breeding. One of the first attempts to transfer genes conferring resistance to root-knot nematodes from $S$. peruvianum to tomato cultivars yielded a cultivated tomato $\mathrm{F}_{1}$ progeny that were resistant to Meloidogyne spp. (Smith 1944). Crossing tomatoes with $S$. pimpinellifolium resulted in plants resistant to Cladosporium fulvum (Walter 1967). Khargongar et al. (2013) crossed tomatoes with $S$. peruvianum and $S$. pimpinellifolium, which have valuable genes conferring resistance to Fusarium wilt and tolerance to early blight and abiotic stress. These authors found that several crossing combinations with $S$. peruvianum made it possible to produce hybrid plants but that immature embryos needed to be cultured. The wild species $S$. peruvianum is resistant to TSWV (tomato spotted wilt virus), and tomato hybrids with $S$. peruvianum have been found to be resistant to this virus, which affects tomato production around the world (Sohrab et al. 2015). The process of transferring genes from wild to cultivated species is often difficult. The hybrids frequently carry "blocks" of desirable and undesirable attributes, and the recovery of important genes is possible by several backcrosses. Also decrease of resistance along back crossing is a known fact. In order to achieve a high degree of resistance in produced varieties, more than one resistance source from wild species could be used in plants susceptible to pathogens (Kalloo 1991). Therefore, new cross combinations could be very valuable in tomato breeding.

Crossability studies of tomato plants with other species is widely described in the literature. Tomato is hybridized with e.g. S. pimpinellifolium, S. habrochaites S. Knapp \& D.M. Spooner, S. cheesmaniae (L. Riley) Fosberg, S. chilense (Dunal) Reiche, S. peruvianum, S. chmielewskii (C.M. Rick, Kesicki, Fobles \& M. Holle) D.M. Spooner, G.J. Anderson \& R.K. Jansen or S. pennellii Correll. Interestingly, some F1 hybrids that resulted after cross combinations e.g. with S. habrochaites or S. pimpinellifolium, were morphologically similar to the wild parents (Kalloo 1991). Several papers have also described the development of somatic, interspecific hybrids regenerated from fused protoplast e.g. with S. tuberosum L. (Melchers et al. 1978) or S. rickii Corr. (O'Connell and Hanson 1986).

Solanum sisymbriifolium Lam. $(2 \mathrm{n}=24)$, also called sticky nightshade (Erhard et al. 2002), belongs to the Cryptocarpum section of the Solanaceae family (Weese and Bohs 2007). It is a self-sterile species (D’Arcy 1974). Solanum sisymbriifolium originated in South America, where it is used as an ornamental plant 
(https://npgsweb.ars-grin.gov/gringlobal/taxonomy detail.aspx?992101521). It is also a useful source of resistance to $R$. solanacearum wilt, $V$. dahliae wilt, root-knot nematodes, and carmine spider mites (Alconero et al. 1988; Collonnier et al. 2003). Resistance to these pathogens is desirable for cultivated eggplants and tomatoes, both of which are highly susceptible to the pathogens. Collonnier et al. (2003) found that interspecific somatic hybrids of eggplants and $S$. sisymbriifolium were more resistant than unhybridized eggplants to $R$. solanacearum bacteria.

The crossability of tomato with $S$. sisymbriifolium is still not fully understood. Several reports indicate the potential of $S$. sisymbriifolium usage for production of tomato haploids via gynogenesis induced by the cross-pollination (Chambonnet 1996, 2012; Bal and Abak 2003). Bal and Abak (2003) observed that the cells of plants regenerated from embryos resulting after crossing were diploid $(2 \mathrm{n}=24)$ or even had 25 and 26 chromosomes. Chambonnet (1996) observed a haploid $(\mathrm{n}=12)$ and diploid number of chromosomes in the obtained progeny. Bal and Abak (2003) suggest that regenerants with complete, diploid chromosomes which they obtained, could be double haploids resulting from spontaneous chromosome doubling. The authors noticed that the development of diploid seedlings formed after crossing was similar to the control tomato, although the stem and cotyledons were thicker and the original leaves had more lobes (Bal and Abak 2003). Chambonnet (2012) showed that after crossing tomato with $S$. sisymbriifolium embryos inside one fruit could be found at various stagesfrom globular pro-embryos to heart-shaped or torpedo-shaped ones. The author noticed also that the embryos were usually small, differently shaped and grew slowly when compared to the control. Plantlets originated from the torpedo embryos were weaker, grew more slowly and had short internodes, their roots comprised of haploid and diploid cells. On the basis of the observations the author suggests that the obtained progeny could have a gametic origin (Chambonnet 2012).

In preliminary studies of the in vivo cross pollination of tomato and S. sisymbriifolium we found that the tomato set fruits with diploid embryos and endosperm within them. Embryo growth was inhibited at the globular stage which can be attributed to a manifestation of postzygotic barriers. The presence of the remnants of the foreign pollen tubes inside the embryo sacs and the presence of male gametes near the tomato egg cell and central cell nuclei seemed promising. Bearing in mind the results obtained by Chambonnet (1996, 2012) and Bal and Abak (2003) as well as our idea that obtaining hybrid progeny could be possible in this cross combination, we developed an in vitro method of culturing immature embryos through the intermediate callus phase and by regenerating hybrid plants.

\section{Materials and methods}

Plant material and crossing technique

Fertile S. lycopersicum plants were used for the analysis of the embryo and endosperm development (control). For the interspecific crosses, male-sterile cultivated $S$. lycopersicum 8450-10 plants were used as female parents, and fertile $S$. sisymbriifolium MM568 (from INRA UR1052) were used as male partners. The plants of both partners used in the experiments, were cutting of the same individual. The fertile $S$. sisymbriifolium plants did not produce seeds and fruits (self-sterile).

For the crossing attempts, the male-sterile $S$. lycopersicum plants were used (instead of the fertile ones) for several reasons. Tomato is self-pollinating species - the pollination of stigma had taken place sometimes even in closed flower buds. Usually in the opened flowers, stigmas were already pollinated. Therefore the crossing experiments using the fertile, female tomato would be difficult, more time-consuming (e.g. anthers removal) and the results could be unclear. The male-sterile $S$. lycopersicum plants used for crossing formed the anthers, although the mature pollen grains did not develop. Therefore we were sure that all of obtained embryos were not developed after accidentally self-pollination.

Flowering plants in pots, obtained from Rijk Zwaan R\&D (Fijnaart, The Netherlands), were kept in a growth chamber with a 16/8 h light/dark photoperiod (the lights were switched on at 06:00 and off at 22:00). The day and night temperatures were $24 \pm 1$ and $18{ }^{\circ} \mathrm{C}$, respectively. The photosynthetic flux density was $250-300 \mu \mathrm{mol} \mathrm{m} \mathrm{m}^{-2} \mathrm{~s}^{-1}$, and this was provided by cool-white fluorescent lamps. The relative humidity was $40 \%$. 
Closed flower buds (1 day before anthesis) and opened flowers of male-sterile tomatoes were chosen for pollination. Flowers were emasculated by hand to make the pollination easier because tomato anthers closely surrounded the whole pistils with stigma. The pistils with receptive stigmas were pollinated in vivo using a very small needle. Hand pollination was performed between 09:00 and 11:00 using fresh pollen grains collected from the opened flowers of $S$. sisymbriifolium. Each pollinated tomato flower was labelled using a coloured marker. The germination of pollen grains on the tomato stigmas was examined microscopically under UV light after aniline blue dye ( $1 \% \mathrm{w} / \mathrm{v}$ in $\mathrm{H}_{2} \mathrm{O}$, at $\mathrm{pH}$ 7.2; Sigma) had been applied. The interspecific crosses were produced in 2014 and 2015.

Histological analysis of the embryos and endosperm

Control and interspecific pollination was performed, then flowers or fruits were sampled between $6 \mathrm{~h}$ and 35 day after pollination (dap). Young fruits were fixed in FAA solution $(90 \mathrm{~mL}$ of $70 \%$ ethanol $+5 \mathrm{~mL}$ of formalin $+5 \mathrm{~mL}$ of glacial acetic acid) for 1 day, then dehydrated in a graded series of ethanol solutions. Ovaries dissected from the fruits were opened and the ovules were removed. Each sample to be analysed was then embedded in a paraplast block and cut into $12 \mu \mathrm{m}$ thick sections using a microtome (Reichert, Germany). Each section was stained with iron haematoxylin (3 $\mathrm{g}$ in $500 \mathrm{~mL}$ of $80 \%$ ethanol; Merck) and fast green FCF (0.3 g in $100 \mathrm{~mL}$ of clove oil; Sigma). These slides were classed as permanent slides. Embryos were also analysed on squashed slides, stained with acetocarmine ( $1 \%$ carmine in $45 \%$ glacial acetic acid; Sigma).

\section{Embryo culture}

The embryo-rescue technique was used to overcome the inhibition of hybrid embryo development. Fruits were harvested 14-35 dap and washed in tap water for $5 \mathrm{~min}$, then the fruits were disinfected in $2 \%$ active chlorine in water for $10 \mathrm{~min}$ and rinsed five times with sterile distilled water. They were then opened aseptically, followed by removal of both the gelatinous ovule coatings and the enlarged ovules. Embryos were extracted from the ovules and cultured in Petri dishes
(5 $\mathrm{cm}$ diameter) containing modified MS medium (Murashige and Skoog 1962). Initially, the embryos were cultured on 20 modified MS media containing phytohormones (zeatin, kinetin, 2.4-D, gibberellic acid, 6-benzylaminopurine, thidiazuron, indole-3acetic acid) and additives (coconut milk, casein hydrolysate) in various concentrations and combinations. Most embryos were cultured directly on the media but some were cultured on tomato endosperm isolated 12-15 dap from the self-pollinated flowers. Due to the fact that the embryos did not respond or degenerate in vitro on a part of the used media, only 9 media (containing zeatin and 2.4-D which induced callus proliferation) were selected for further experiments (Table 1). The cultures were kept in a climate chamber (Mytron) using a $16 \mathrm{~h}$ photoperiod (with a photosynthetic flux density of $300 \mu \mathrm{mol} \mathrm{m}^{-2} \mathrm{~s}^{-1}$ ). The day and night temperatures were 20 and $16{ }^{\circ} \mathrm{C}$ respectively, and the relative humidity was $75 \%$. The cultures were checked at regular intervals, and the number of embryos that responded (or not) on the media were counted.

\section{Plantlet regeneration}

The calli that developed from the embryos were transferred to selected regeneration MS media not containing 2.4-D (Table 2). Well-formed rooted plantlets were excised from each callus and transferred to tap water containing micronutrients, macronutrients, and iron (at half the concentrations in the MS medium). After 10-14 days of hardening, the plantlets were transferred to pots with garden soil (Kronen) and adapted to the culture room conditions.

\section{Morphological observations of regenerants}

The morphology of leaves, shoots and flowers of parents and hybrid plants were analysed under the stereomicroscope. The compared plants were of the same age. Measurements of the prickle lengths of the examined species were performed using Axiovision 8.1 Software. From every 3 plants of 3 examined species (parents and hybrids) 15 prickles were selected from the medial part of the main shoot and measured. Statistical analyses were performed by the Student's $t$ test using Statistica 10 software (Tulsa, USA). 
Table 1 MS media used to induce callus development from the cultured embryos

\begin{tabular}{|c|c|c|c|c|c|c|c|}
\hline \multicolumn{5}{|c|}{ Growth regulators $\left(\mathrm{mg} \mathrm{l}^{-1}\right)$} & \multirow[t]{2}{*}{ Coconut milk $\left(\mathrm{ml} \mathrm{1}^{-1}\right)$} & \multirow[t]{2}{*}{ Sucrose $\left(\mathrm{g}^{-1}\right)$} & \multirow{2}{*}{$\begin{array}{l}\text { Callus induction } \\
\text { overall } 176 \text { embryo }\end{array}$} \\
\hline KIN & BAP & ZEA & 2.4-D & IAA & & & \\
\hline- & - & 1.0 & - & - & - & 60 & 9 embryos \\
\hline- & - & 1.0 & 1.0 & - & - & 30 & 18 embryos \\
\hline- & - & 1.0 & 1.0 & - & - & 60 & 36 embryos \\
\hline- & - & 1.0 & 1.0 & - & - & 90 & 24 embryos \\
\hline- & - & 1.0 & 2.0 & - & - & 30 & 22 embryos \\
\hline- & - & 1.0 & - & 0.5 & - & 20 & 14 embryos \\
\hline- & - & 1.0 & - & - & 10.0 & 30 & 12 embryos \\
\hline - & - & 2.0 & 1.0 & - & - & 30 & 27 embryos \\
\hline - & - & 2.0 & 2.0 & - & - & 30 & 14 embryos \\
\hline
\end{tabular}

Table 2 Optimum media for regenerating plantlets in vitro from the calli

\begin{tabular}{|c|c|c|c|c|c|c|c|}
\hline \multicolumn{6}{|c|}{ Growth regulators $\left(\mathrm{mg} \mathrm{l}^{-1}\right)$} & \multirow[t]{2}{*}{ Sucrose $\left(\mathrm{g}^{-1}\right)$} & \multirow{2}{*}{$\begin{array}{l}\text { Plantlets regeneration } \\
\text { overall } 50 \text { plantlets }\end{array}$} \\
\hline KIN & BAP & ZEA & 2.4-D & IAA & NAA & & \\
\hline 0.5 & - & - & - & - & 1.0 & 30 & 2 plantlets \\
\hline 1.0 & - & - & - & 0.1 & - & 20 & 2 plantlets \\
\hline 1.0 & - & - & - & 0.5 & - & 30 & 2 plantlets \\
\hline 1.0 & - & - & - & - & 0.5 & 30 & 3 plantlets \\
\hline- & 0.01 & - & - & 0.01 & - & 20 & 10 plantlets \\
\hline- & 0.5 & - & - & - & - & 30 & 2 plantlets \\
\hline - & 1.0 & 0.5 & - & 0.5 & - & 30 & 3 plantlets \\
\hline- & - & 1.0 & - & - & - & 60 & 5 plantlets \\
\hline - & - & 1.0 & - & 0.1 & - & 20 & 7 plantlets \\
\hline- & - & 1.0 & - & 0.5 & - & 20 & 9 plantlets \\
\hline - & - & 2.0 & - & - & - & 30 & 3 plantlets \\
\hline - & - & - & - & 0.5 & - & 30 & 2 plantlets \\
\hline
\end{tabular}

\section{KASP analysis}

The hybrid nature of the embryo-rescued plants was confirmed by using the Kompetitive Allele Specific PCR (KASP ${ }^{\mathrm{TM}}$ ) method, which was developed by LGC Genomics (Berlin, Germany; http://www. lgcgroup.com/kasp/\#.WhvZdlXiaUk), following the manufacturer's instructions. The analyses were performed by the Rijk Zwaan Company (Fijnaart, The Netherlands). S. sisymbriifolium (3 plants), S. lycopersicum (4 plants), and 8 regenerants (individuals) obtained after the crossing procedure were analysed using SNP markers. Initially 375 tomato SNP-markers were tested, out of which 33 showed polymorphic results in $S$. lycopersicum and $S$. sisymbriifolium. From the 33 markers, 7 allocated on different chromosomes were chosen. The localization of the selected SNP markers TOM1-TOM7 (Table 3) was determined from the physical tomato genome map (Genome version SL3.0). For the development of prime sequences, the tomato Genome version 2.50 (August 8.2016; solgenomics.net) was used. PCR was performed using a solution containing the KASP reaction mix, the assay mix, and template DNA. Endpoint genotyping was performed using fluorescence measurements using KlusterCaller software (LGC 
Table 3 SNP markers and their chromosome localizations (with reference Genome version SL3.0)

\begin{tabular}{llllllll}
\hline SNP & Localization & & \multicolumn{2}{l}{ S. sisymbriifolium } & & \multicolumn{2}{l}{ S. lycopersicum } \\
& & & KASP result & SNP & & KASP result & SNP \\
\hline TOM1 & SL3_0ch10 & 62691787 & B & G & & A & A \\
TOM2 & SL3_0ch03 & 65558479 & A & A & & B & G \\
TOM3 & SL3_0ch05 & 60946473 & A & T & B & C \\
TOM4 & SL3_0ch11 & 7930489 & B & G & A & A \\
TOM5 & SL3_0ch02 & 48608431 & A & T & B & C \\
TOM6 & SL3_0ch07 & 2870607 & B & G & A & A \\
TOM7 & SL3_0ch04 & 55646480 & B & G & A & C \\
\hline
\end{tabular}

Genomics). The homozygote A was marked red, homozygote $\mathrm{B}$ blue, and heterozygote $\mathrm{AB}$ green.

Flow cytometry

The nuclear genome size of $S$. lycopersicum, $S$. sisymbriifolium and their hybrids was determined using a Cytomics FC500 (Beckman Coulter) flow cytometer with an $488 \mathrm{~nm}$ argon laser. The leaves of the examined plants were washed 3 times in distilled water. Due to the significant differences in the amount of DNA between the parental plants and the internal standards availability, 2 internal standards were used. The leaves of $S$. lycopersicum were simultaneously chopped with $1 \mathrm{~cm}^{2}$ leaf of internal standardRaphanus sativus L. "Saxa" 2C $=1.11$ pg (Dolezel et al. 1992) and the leaves of S. sisymbrifolium or hybrids with Pisum sativum "Ctirad" $2 \mathrm{C}=9.09 \mathrm{pg}$ (Dolezel et al. 1998). The samples were chopped using ice-cold Galbraith's buffer (Galbraith et al. 1983) containing $0.1 \%$ Triton, $1 \%(\mathrm{w} / \mathrm{v})$ polyvinylpyrrolidone 40,000 and $5 \mu \mathrm{l} / \mathrm{ml}$ 2-mercaptoethanol. The suspensions were filtered through $30 \mu$ m nylon mesh (CellTrics, Sysmex Partec) and $50 \mu \mathrm{l} / \mathrm{ml}$ RNAse was added. Nuclei were stained with $50 \mu \mathrm{l} / \mathrm{ml}$ propidium iodide and incubated on ice for $10-15 \mathrm{~min}$. The analysis was performed on 3 plants of $S$. lycopersicum, 3 plants of $S$. sisymbriifolium and 8 hybrid individuals. The parental and hybrids plants were measured separately with 5 repetitions-at least 5000 nuclei were analysed. The amount of DNA of the examined species was calculated based on values of G1 peak means of samples and internal standard.

\section{Results} (control)

The pollen grains of $S$. lycopersicum has already begun to germinate on stigmas $6 \mathrm{~h}$ after pollination (Fig. 1a). Approximately $10 \mathrm{~h}$ later, pollen tubes grew on stigmas with about $90 \%$ frequency. Long pollen tubes penetrated the styles (Fig. 1b) and entered the micropyle region of the embryo sac 1 dap (Fig. 1c). Often, the two male gametes were present at the tip of the unburst, thick pollen tubes or near the egg cell and central cell nuclei/polar nuclei (Fig. 1c). Unfortunately, during our embryological analysis we could never observe the fertilization process of both egg cell and central cell however we presume that this process occurs between 1 and 2 dap. The first endosperm nuclei were observed inside the embryo sacs 2 dap (Fig. 1d). Well developing cellular endosperm comprising 6-7 cells were visible 1 day later. During the following days, the endosperm cells divided intensively and filled the embryo sacs. At the same time, the four-celled embryos were visible (3-4 dap). Over the next few days the ovules intensively enlarged. Globular embryos with properly developed suspensor were present 8 dap (Fig. 1e) and heart-shaped ones around 14-15 dap (Fig. 1f). The growing embryos consumed the endosperm intensively, whose remnants were localized usually at the polar parts of the embryo sacs. Highly elongated cotyledonary embryos were visible 21-22 dap (Fig. 1g).

Interspecific crossing and fruit setting

The pollen grains of $S$. sisymbriifolium started to germinate on tomato stigmas $6 \mathrm{~h}$ after cross
Development of tomato embryo and endosperm 


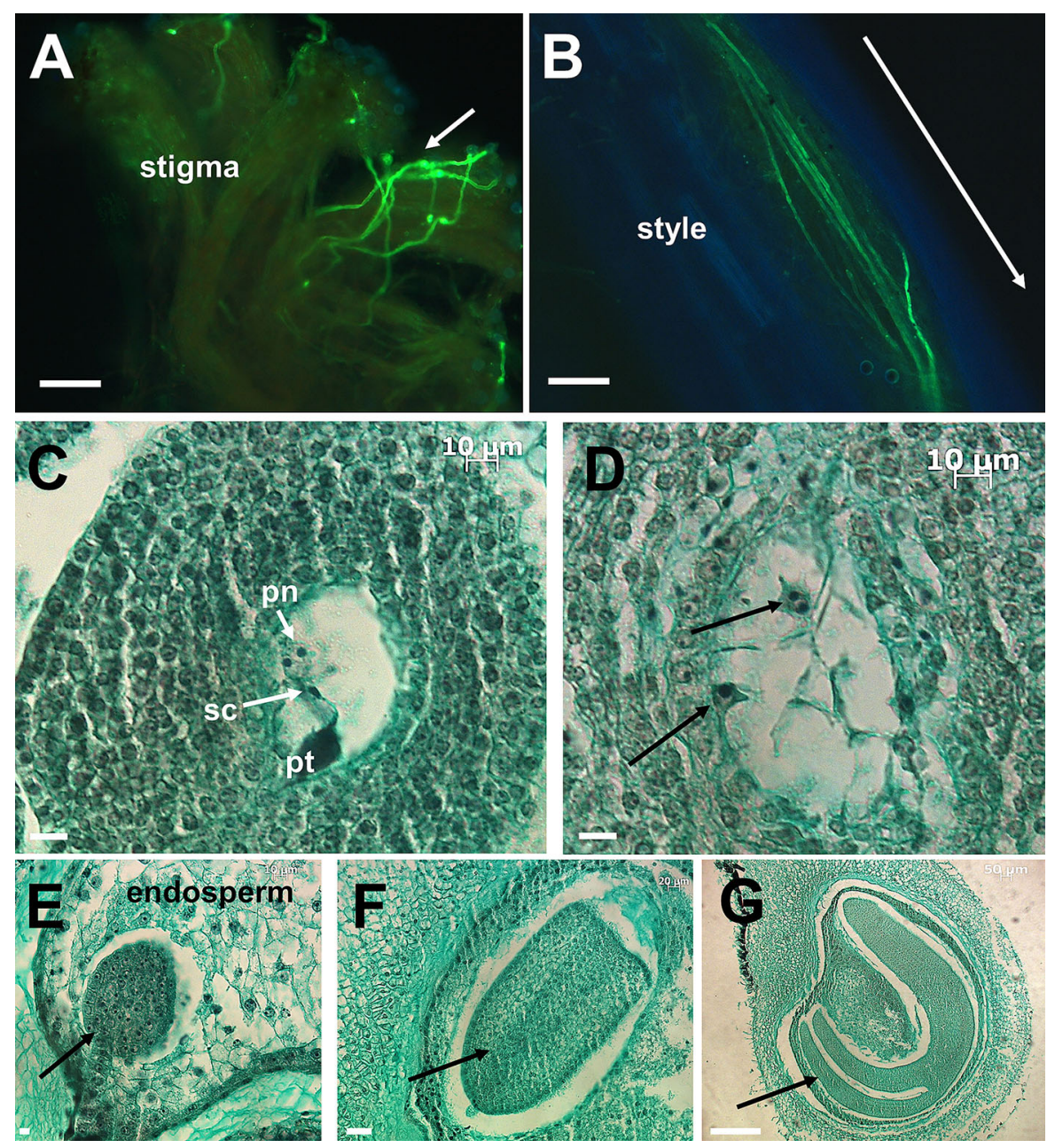

Fig. 1 The development of embryo and endosperm of $S$. lycopersicum (control). a Pollen tubes germinated on stigma $6 \mathrm{~h}$ after pollination. b Pollen tubes penetrated the style 1 dap, the arrow indicates the direction of pollen tubes growth. c The entrance of pollen tube (pt) with visible sperm cell (sc) 1 dap.

pollination. Up to $80 \%$ of the S. sisymbriifolium pollen grains germinated on receptive tomato stigmas 1 dap (Fig. 2a), when pollination was performed between 09:00 and 10:00. The pollen germination efficiency was only $50 \%$ when pollination was performed later on. Some of the germinated pollen grains produced short pollen tubes which did not enter the styles, were curved and distended at the tip. Pollen tubes (appropriate for the lengths of $S$. sisymbriifolium styles, which are 2-3 times longer than tomato pollen tubes), penetrated between papillae cells and grew through the stylar connecting tissue (Fig. 2b) to the ovules (anatropous, unitegmic, tenuinucellate Polygonum-
Polar nuclei (pn) are present. d Endosperm nuclei developed 2 dap. e Globular embryo developed 8 dap. f Heart-stage embryo formed 15 dap. g Cotyledonary embryo 22 dap. Each scale bar $10 \mu \mathrm{m}$

type megagametophytes) and entered the embryo sacs, destroying one of the synergids 1-2 dap (Fig. 2c). The embryological slides showed that the sperm cells were near the egg cells or central cells or remained inside the unburst pollen tubes. Similarly to the control material, we did not notice the fertilization process of both egg and central cell, although we presume that it may occur at the same time as in the control material (1-2 dap). At 2-3 days following pollination we occasionally observed dividing central cells (Fig. 2d) which may be a sign that the fertilization had taken place. The first endosperm nuclei appeared about 3 dap (Fig. 3a). The endosperm divided intensively and 

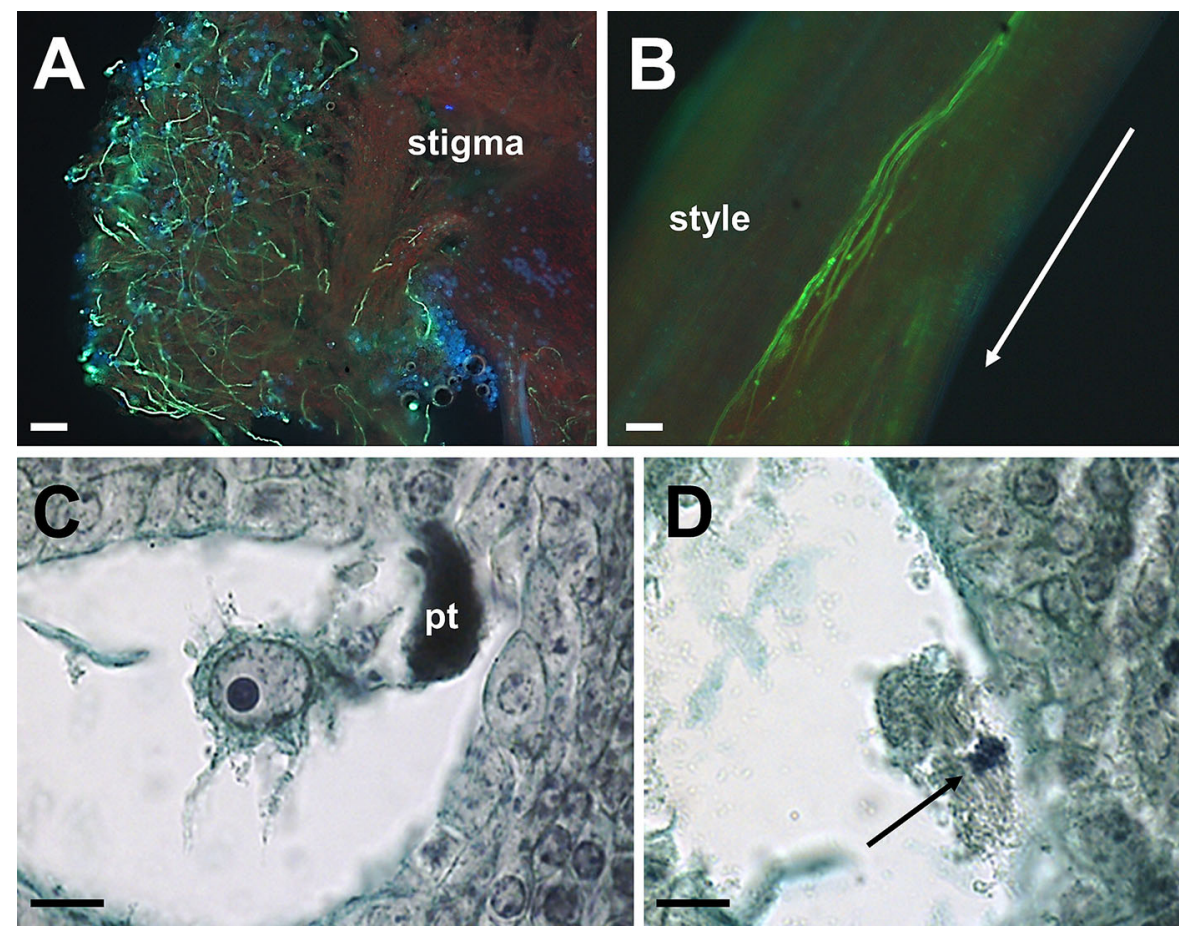

Fig. 2 Progamic phase of the $S$. lycopersicum $\times S$. sisymbriifolium crossing pollination. a, $\mathbf{b}$ S. sisymbriifolium pollen tubes penetrated the stigma and style 1 day after cross pollination (dap). Arrow indicates the direction of pollen tube growth. $\mathbf{c}$ The

simultaneously surrounded the developing embryos (Fig. 3d). The hybrid endosperm structures (highly vacuolized large cells; Fig. 3d) were not generally different from the endosperm structures in the control material but sometimes contained small flattened cells with very dense cytoplasm. The endosperm did not develop in some of the embryo sacs that were analysed.

Embryos analysed $<22$ dap often contained a few cells and had well-formed suspensors, however some of them degenerated early (Fig. 3b). The development of hybrid embryos stopped at the globular stage (Fig. 3c) despite high mitotic activity. Some embryos retained the globular structure even one month after crossing (Fig. 3d). Instead of developing properly to the heart stage, some of the globular stage embryos increased in size in vivo and sometimes almost entirely filled the embryo sac, consuming the endosperm (Fig. 3d). Some of the oversized embryos started to collapse four weeks after pollination (Fig. 3e), probably due to a lack of endosperm. The squashed slides of the hybrid embryos revealed a pollen tube (pt) entered the embryo sac 2 dap. d Division of central cell nuclei (presumably fertilized) 2 dap. The scale bars in $\mathbf{a}$ and $\mathbf{b} 50 \mu \mathrm{m}$, and the scale bars in $\mathbf{c}$ and $\mathbf{d} 10 \mu \mathrm{m}$

diploid $(2 \mathrm{n}=24)$ number of chromosomes in their dividing cells. We did not observe a haploid $(\mathrm{n}=12)$ number of chromosomes or any signs of aneuploidy. The failure to complete embryo development can be attributed to post-zygotic incompatibility.

Interspecific crossing resulted in a relatively low fruit setting rate, only $9.26 \%$ of the 3561 pollinated flowers producing fruits. The ripe fruits were generally slightly smaller than the control fruits. In summary, we obtained 1289 globular embryos from which 1109 were used for the in vitro cultures and the rest for the embryological analysis (squashed and permanent slides). Only four of the observed in vivo embryos reached the early heart stage (Fig. 3f).

Culturing the embryos

To overcome embryo development inhibition, globular embryos were removed from the ovules and transferred to the media. About $50 \%$ of the fruits were parthenocarpic, filled with parenchyma tissue. Around 120 fruits (isolated 20-35 dap) had ovules 

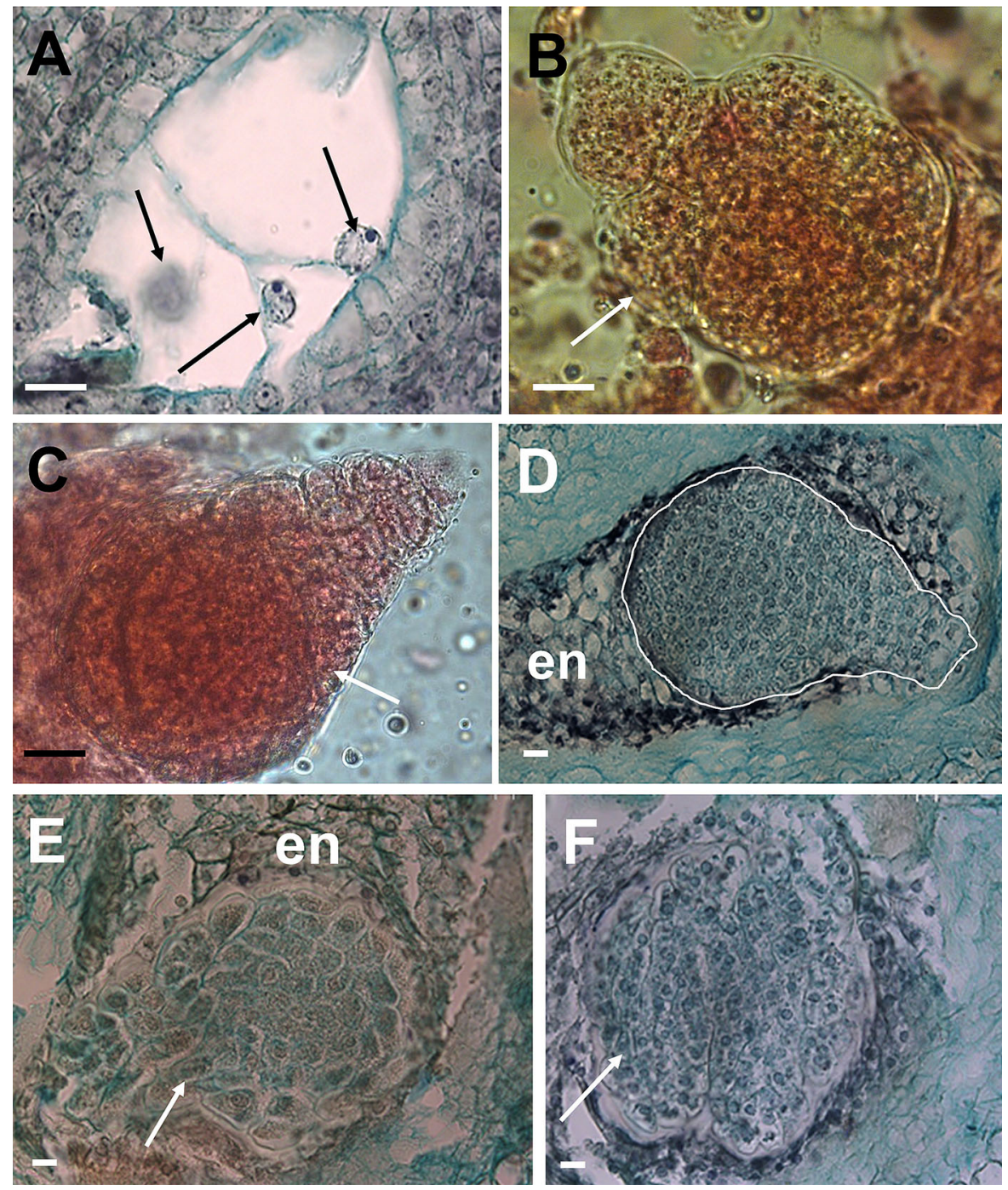

Fig. 3 Development of the endosperm and embryos after crossing. a Three-celled endosperm (arrows) developed 3 dap. b Early degenerating embryo 16 dap. c Globular embryo 16 dap. d Embryo surrounded by the cellular endosperm (en) 27 dap.

with immature embryos that were suitable for being cultured further. The number of enlarged ovules per fruit was highly variable, from as few as one to as many as 30 . Brown, wrinkled, very enlarged ovules containing oversized globular embryos were found in some fruits, especially isolated 30-35 dap.

At the beginning we attempted to use the nurse technique in the first weeks of the experiment, cultivating 139 hybrid embryos overall directly on tomato endosperm (isolated 12-15 day after selfing; Fig. 4b). The nurse technique was used e.g. Ziebur and
The white line indicates the shape of embryo. e Degenerating embryo and the remnants of the endosperm (en) 35 dap. f Degenerated early heart-shaped embryo 28 dap. Each scale bar $10 \mu \mathrm{m}$

Brink (1951) who recorded the successful growth of Hordeum embryos on the isolated, cellular endosperm. In our work, the tomato endosperm became brown very quickly and started degenerating, as did the "nursed" embryos. The failure of the nurse-technique attempts led us to attempt to culture 970 globular embryos directly on the selected media (Fig. 4a).

The embryo response in vitro depended on the embryo age and composition of the medium. Most (757) of the cultured embryos (on media without the zeatin and 2.4-D) did not respond on the used media. 


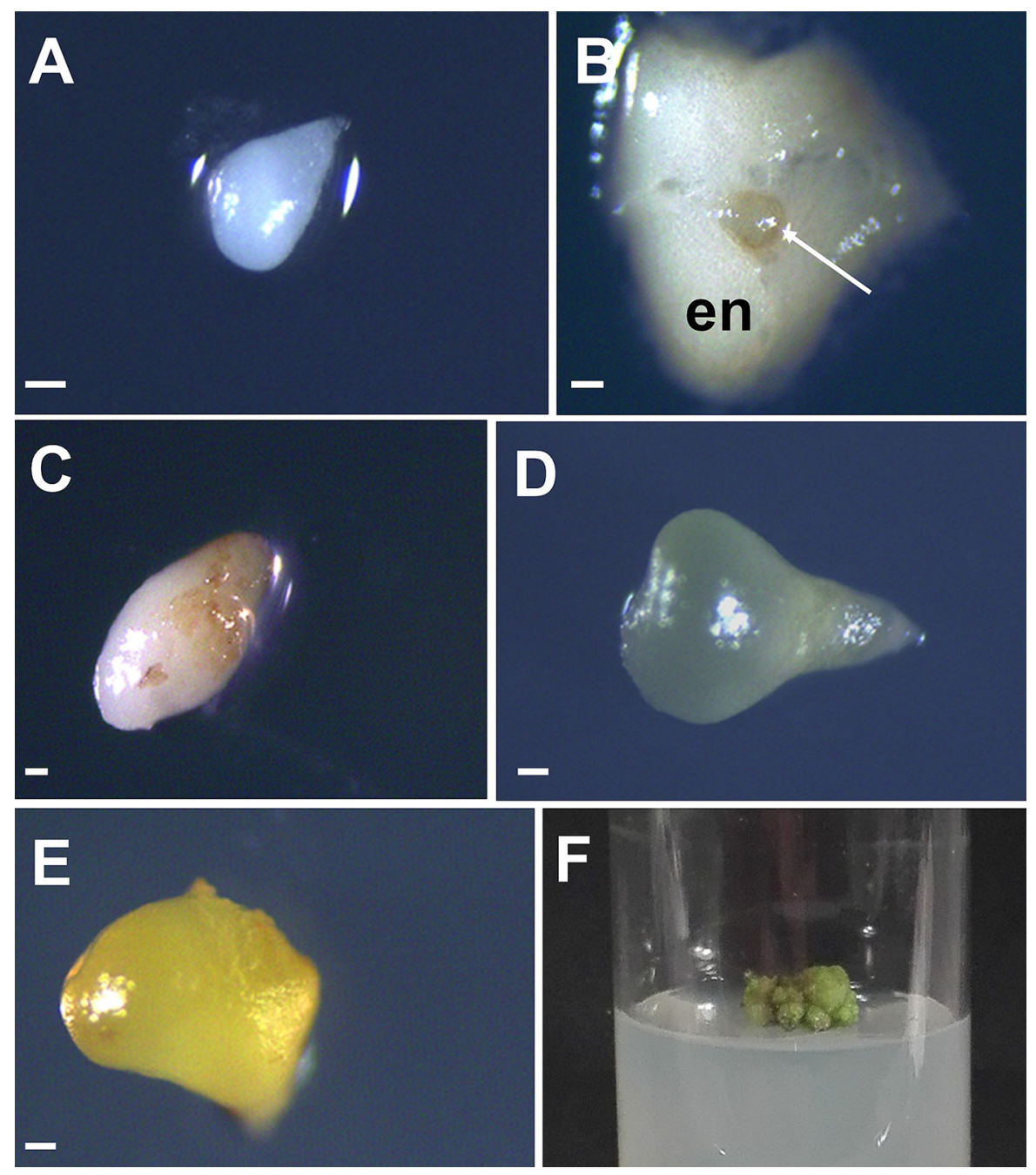

Fig. 4 In vitro culture of hybrid embryos. a Embryo isolated 32 days after cross pollination (dap) cultured on MS medium. b Globular embryo isolated 25 dap (indicated by an arrow), cultured on tomato endosperm (en). c and d Enlarged embryos after 8 day of culture on MS medium containing 2.4-D

Several (12) embryos which were generally isolated $<20$ day after crossing died during the first few days of culture. Media with zeatin and 2.4-D induced the magnification of 21 embryos (sometimes 3-4 times), however growth stopped soon afterwards (Fig. 4c, d).

During the culture some embryos produced morphogenic callus on media containing zeatin and 2.4-D in various combinations, therefore for further experiments we decided to use only 9 media, which effectively induced callus regeneration (Table 1). In total 176 cultured immature embryos (mainly isolated $\left(2 \mathrm{mg} \mathrm{l}^{-1}\right)$ and ZEA $\left(1 \mathrm{mg} \mathrm{l}^{-1}\right)$. e Callus from an embryo after 16 day of culture. f Morphogenic callus after 62 day on MS medium containing ZEA $\left(1 \mathrm{mg} \mathrm{l}^{-1}\right)$ and IAA $\left(0.5 \mathrm{mg} \mathrm{l}^{-1}\right)$. Each scale bar $100 \mu \mathrm{m}$

20-22 dap) developed a callus. These embryos changed colour from milky white to green in the first few days of culture and calli started to proliferate intensively (Fig. 4e). The MS medium containing $1 \mathrm{mg}^{-1}$ ZEA and $1 \mathrm{mg} \mathrm{l}^{-1}$ 2.4-D was the optimal medium for stimulating callus growth.

Only four cultured globular embryos (around 25 day old) grew directly into plantlets on three different media, two grew on $\mathrm{MS}+0.5 \mathrm{mg} \mathrm{l}^{-1} \quad \mathrm{GA}_{3-}$ $+0.5 \mathrm{mg} \mathrm{l}^{-1} \mathrm{BAP}+10 \%$ coconut milk (containing $6 \%$ sucrose), one on $\mathrm{MS}+1 \mathrm{mg} \mathrm{l}^{-1}$ $\mathrm{BAP}+250 \mathrm{mg}^{-1}$ casein hydrolysate (containing 
$4 \%$ sucrose), and the last one grew on MS $+1 \mathrm{mg} \mathrm{l}^{-1}$ $\mathrm{ZEA}+0.5 \mathrm{mg} \mathrm{l}^{-1}$ IAA (containing $2 \%$ sucrose). Unfortunately, these plantlets did not survive the acclimatization.

\section{Regeneration of hybrid plants}

Well-developed, compact, green, morphogenic calli (Fig. 4f) were split into small pieces and transferred to modified MS medium containing no 2.4-D (Table 2). About $15 \%$ of the calli increased in size and produced adventitious buds. Yellowish/glassy, loose, non-morphogenic calli rarely grew on the green calli. The first shoot and leaf primordia emerged after several days, but regeneration occurred within 2 months (Fig. 5a, b). Overall 50 plantlets were regenerated (Table 2). Most of the plantlets that were recovered in vitro had well-developed roots and main shoots with leaves. Some plantlets formed rosettes with numerous relatively short shoots (Fig. 5b, c). The best media for plantlet regeneration were the MS medium containing $0.01 \mathrm{mg} \mathrm{l}^{-1}$ BAP and $0.01 \mathrm{mg} \mathrm{l}^{-1}$ IAA ( $2 \%$ sucrose) and the MS medium containing $1 \mathrm{mg} \mathrm{l}^{-1} \mathrm{ZEA}$ and $0.5 \mathrm{mg} \mathrm{l}^{-1}$ IAA ( $2 \%$ sucrose).

Plantlets without roots (Fig. 5b) were transferred onto the rooting medium $\mathrm{MS}+0.5 \mathrm{mg} \mathrm{l}^{-1}$ IAA. Roots formed slowly, after 1-2 months. Well-developed and rooted regenerants were transferred to jars (Fig. 5d). Plantlets with 5-6 cm shoots were transferred to water containing macronutrients, micronutrients, and iron (at half the concentrations in the MS medium; Fig. 5e). After a few days, the plants were transferred to soil (Fig. 5f). From the rooted plantlets we obtained 10 plants originating from the different embryos and from the 10 regenerants, 2 plants died a few weeks after their transfer to soil.

\section{Morphology of the regenerants}

The bushy plant habit of the obtained regenerants (Fig. 6b) was similar to that of S. sisymbriifolium (Fig. 6c) rather than to the erect, maternal phenotype (Fig. 6a). The height of the hybrids was slightly lower (up to $50 \mathrm{~cm}$ ) than the paternal plants (around 60-65 cm). Leaves of hybrids were visibly smaller than $S$. sisymbriifolium, with similar morphology (pinnatifid to pinnatisect). Shoots of all species were green (although the $S$. lycopersicum ones had a lighter shade) and covered by grandular simple hair (shorter in hybrids when compared with the parents; Fig. 7ac). Distinguished from the $S$. lycopersicum plants (Fig. 7a, d) and similar to those of $S$. sisymbriifolium (Fig. 7c, f), the prickles were present on shoots and leaves midvein of the hybrid (Fig. 7b, e). The prickles of the hybrids were usually light-brown to dark-brown and soft under the fingers, in contrast to the very sharp and hard prickles of S. sisymbriifolium (yellow from the bottom to dark brown at the top). The differences in prickle length were significant-the hybrids produced prickles over 9 times shorter than S. sisymbriifolium, but the prickles on the hybrids occurred more frequently than in the paternal ones (Fig. 8).

The regenerants produced numerous flowers, but markedly smaller and fewer than flowers of $S$. sisymbriifolium. Corolla of the F1 hybrid flowers were white to light blue corolla with yellow hues near the pistils and stamens as $S$. sisymbriifolium ones. Stamens of the hybrid were equal as long as styles (Figs. 9, 10) and usually free (as in S. sisymbriifolium), however with more loose arrangement than in paternal flowers (Fig. 10e). Only in few of observed hybrid flowers the stamens were fused together and formed a tube which surrounded the styles and stigma similarly to the tomato flowers. The stamens morphology of hybrids was similar to the $S$. lycopersicum and $S$. sisymbriifolium ones with the intermediate length. The hybrid stamens were usually yellow (Fig. 10d) as in $S$. sisymbriifolium (Fig. 10g). Stamens of male-sterile and fertile tomato (morphologically comparable) were usually yellow or greenish at the top (Fig. 10a).

In contrast to the parental material (Fig. 10c, i) the fertile embryo sacs of hybrids (containing well developed egg cell, synergids and central cell nuclei) were present in only $10 \%$ of the analysed flowers (Fig. 10f). Around $90 \%$ of the opened hybrid flowers were female-sterile, with embryo sacs containing only the remnants of the degenerated egg cell and central cell nuclei. In some ovules only the remnants of degenerated megaspore tetrad cells were present. In none of the analysed anthers of hybrid (Fig. 10d) was there any evidence of presence of pollen grains or even microspores. The lack of pollen grains together with the development of sterile embryo sacs (in most of the ovules) are typical attributes of post-zygotic incompatibility. More investigations are necessary to describe at which stage of micro- and megasporogenesis the abnormalities occur in the hybrid plants. 

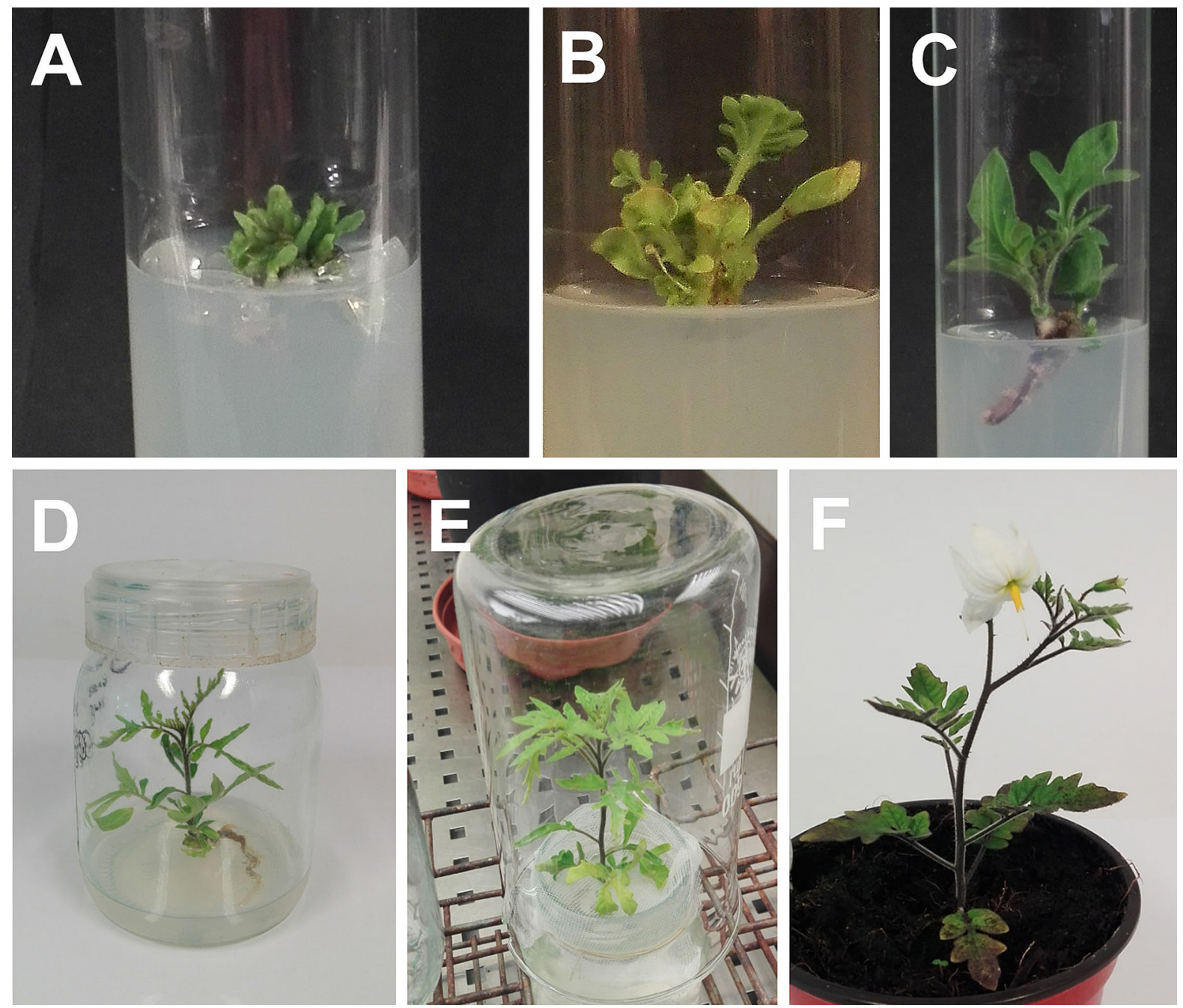

Fig. 5 Regeneration of the hybrid plants. a Leaf rosette originating from a callus after 61 day on MS medium containing ZEA $\left(1 \mathrm{mg} \mathrm{l}^{-1}\right)$ and IAA $\left(0.5 \mathrm{mg}^{-1}\right)$. b Plantlet developed after 110 day of culture on MS medium containing BAP

Flow cytometry and KASP analysis

The flow cytometry analysis confirmed the hybrid status of the 8 tested regenerants. The measured DNA content amount of all the analysed hybrids was intermediate between the parental material. An exemplary result for one selected plant of each species was: S. lycopersicum: $2.11 \pm 0.13 \mathrm{pg}$ (Fig. 11a); hybrid: $2 \mathrm{C}=3.65 \pm 0.01 \mathrm{pg}$ (Fig. 11b); S. sisymbriifolium$5.06 \pm 0.03$ (Fig. 11c).

The KASP genotyping analysis also confirmed that the eight regenerants tested were hybrids. The KASP analysis cluster plot of the TOM2 SNP marker showed $\left(0.01 \mathrm{mg}^{-1}\right)$ and IAA $\left(0.01 \mathrm{mg}^{-1}\right)$. c Plantlet after 25 day on rooting MS medium + IAA $\left(0.5 \mathrm{mg}^{-1}\right)$. d Plantlet transferred to the medium in a jar. e Plant transferred to tap water. f Young flowering hybrid plant in a pot containing soil

that the heterozygote $(\mathrm{AB})$ contained marked SNP (Table 3) for both crossing components (homozygote A was from S. sisymbriifolium and homozygote B from S. lycopersicum; Fig. 12). Analysis of six additional SNP markers proved the hybrid origin of all eight tested regenerants (Table 4).

\section{Discussion}

The method of embryo-rescue technique together with the callus stage was developed successfully which led to the regeneration of hybrid individuals. The topic of 

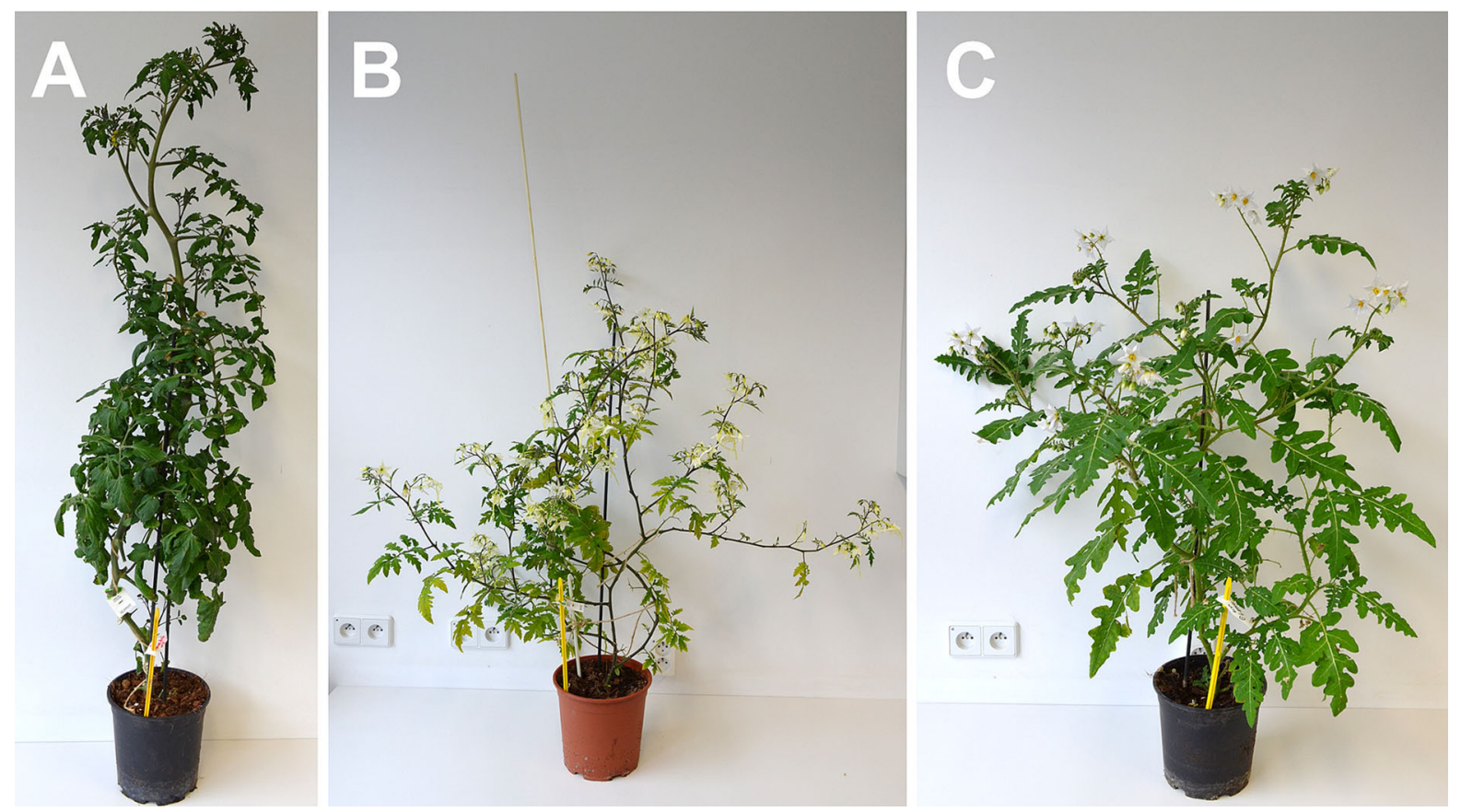

Fig. 6 Plant habit of examined plants. A S. lycopersicum b hybrid c S. sisymbriifolium
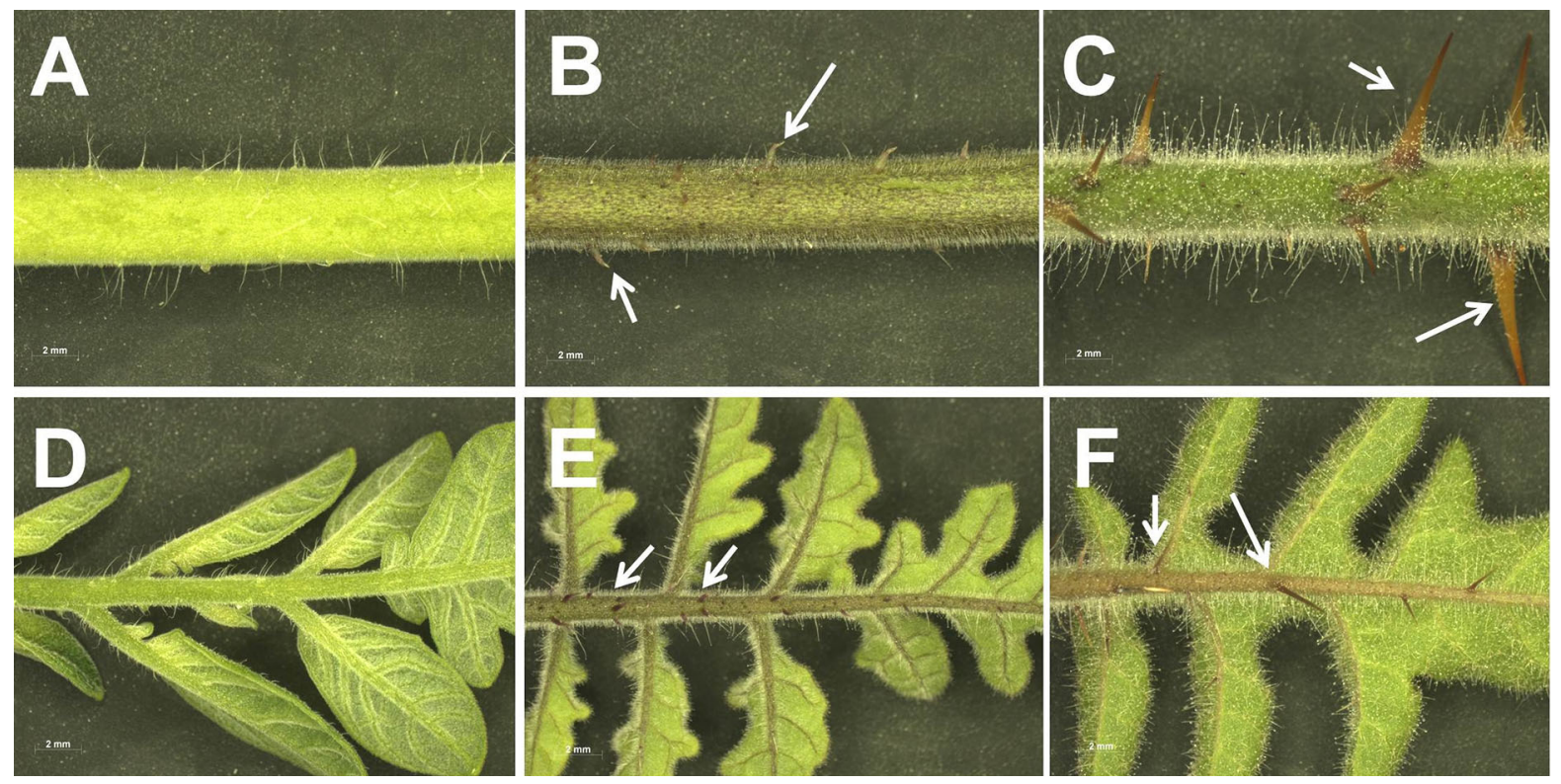

Fig. 7 Morphologies of shoots and leaves (dorsal part) of parents and hybrid plants. a, d shoot and leaf of S. lycopersicum with no prickles. $\mathbf{b}$, e short and numerous prickles formed on

cross combination of $S$. lycopersicum $\times S$. sisymbriifolium is interesting for two reasons. Firstly, the $S$. sisymbriifolium plants show a high resistance to shoots and leaves of hybrid. c, f long prickles developed on shoots and leaves of S. sisymbriifolium. Each scale bar $20 \mu \mathrm{m}$

various pathogens which could be very useful for breeding species. Tomatoes have previously been crossed with their wild relatives such as $S$. peruvianum 
Fig. 8 The length of prickles developed on shoots of S. sisymbriifolium and hybrid (prickles are not presented in $S$.

lycopersicum).

The different

letters indicate significant differences $( \pm \mathrm{SE})$

according to Student's $t$ test

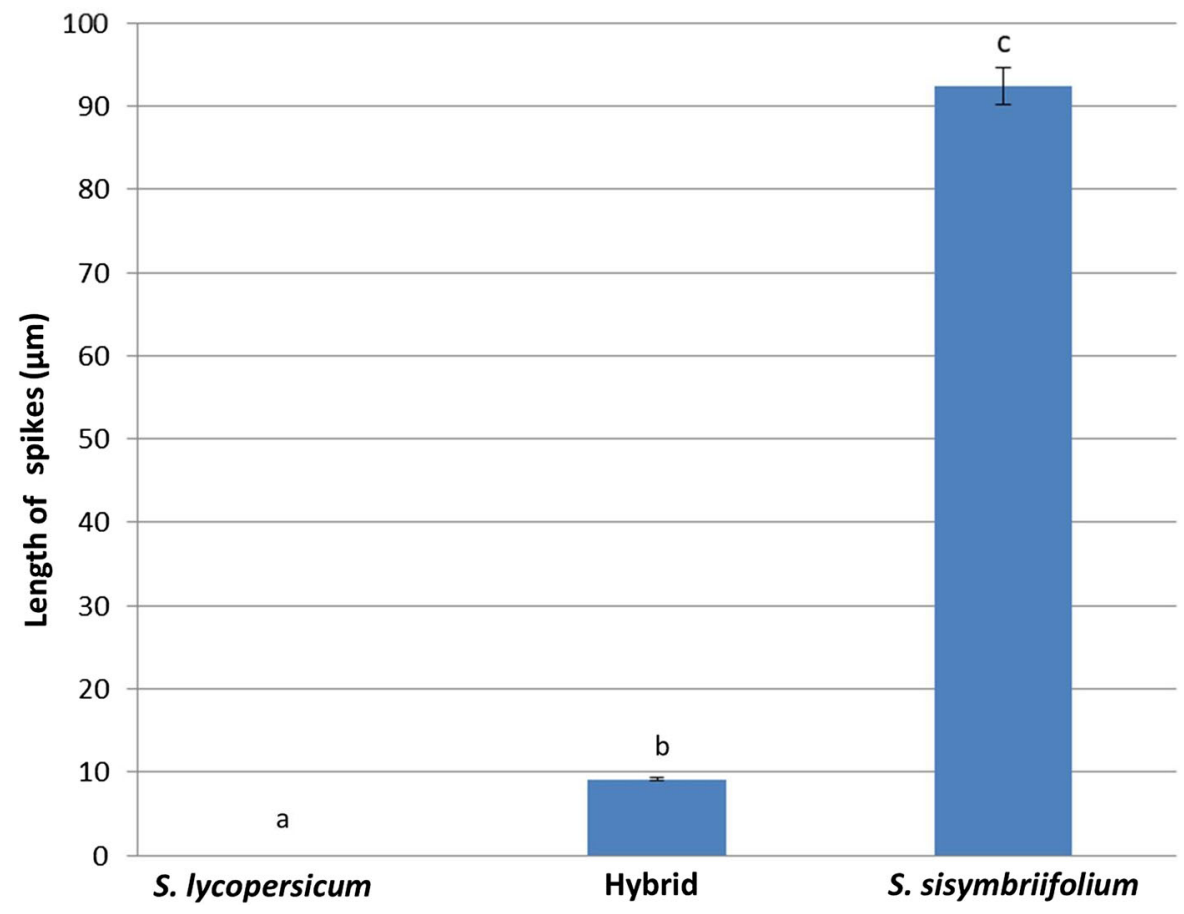

or S. pimpinellifolium in many studies, to transfer genes associated with pathogen resistance. The examined cross combination of $S$. lycopersicum $\times S$. sisymbriifolium also appeared promising for this purpose. Secondly, S. sisymbriifolium has been used in experiments on tomato gynogenic haploid production (Chambonnet 1996, 2012; Bal and Abak 2003) so the results of this research can be discussed with our investigations.

The germination of $S$. sisymbriifolium pollen grains on $S$. lycopersicum stigmas was frequent and oscillated around 80\% 1 dap. However, observations of the pollinated stigma revealed that many of pollen tube were short, and curled. Only some of the germinated pollen tubes were long and penetrated the whole style. The entrance of the pollen tubes was frequently found in most of the analysed ovules. Bal and Abak reported (2003) that in only 6 of 8 tomato varieties, pollen tubes were visible inside the embryo sacs while in the two remaining cultivars, pollen tubes reached only the middle part of the style. Chambonnet (2012) observed very low germination of $S$. sisymbrifolium pollen grains - the pollen tubes remained within the stigma or reached only the top of the style. Abnormalities in pollen tube development were observed by $\mathrm{Bal}$ and Abak (2003), Chambonnet (2012) and also in our tests, which suggested the presence of prezygotic barriers occurring as early as the pollen germination stage. However, it is also known, that pollen germination and pollen tube growth can be affected by many factors, as plant genotype. Interestingly, De Nettancourt et al. (1973) stated that $S$. peruvianum pollen tubes are compatible with tomato styles and found that they grew uninhibited through the stylar connecting tissue.

In many of our analysed ovules following crossing, pollen tubes were present at the micropyle region of embryo sacs, which was also reported by Bal and Abak (2003). During embryological analysis carried out with accuracy, it was not possible to identify the fertilization process of both egg and central cell nuclei. We were also unable to observe fertilization in the control (tomato material). Likewise, Bal and Abak (2003) were uncertain whether the fertilization took place after crossing. Our further results seemed to indicate that this process does occur, presumably around 1-2 dap.

Interspecific crossing gave a relatively low fruit setting rate $(9.26 \%)$ which may be related to low fertilization frequency. Bal and Abak (2003) found that the fruit setting rate when crossing tomatoes with S. sisymbriifolium varied widely and depended on such factors as genotype and pollination date. Only 


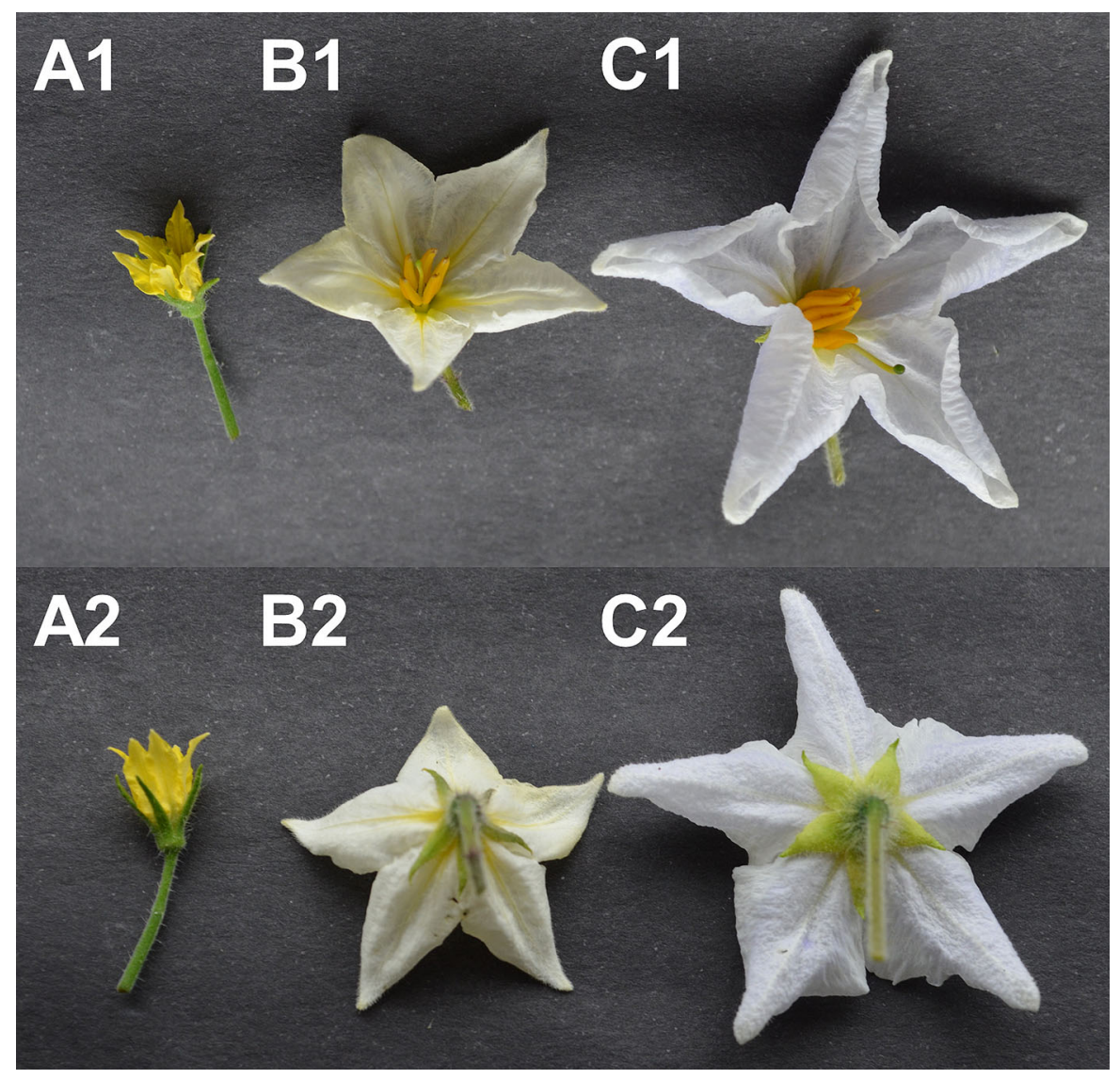

Fig. 9 Morphologies of opened flowers: a1, a2 S. lycopersicum, b1, b2 hybrid, c1, c2 S. sisymbriifolium

some of tested cultivars produced fruits, and the fruit setting rates in April and May were 32.4\% and 17.9\%, respectively (Bal and Abak 2003). Chetelat et al. (1997) found that the number of fruits produced by crosses of $S$. lycopersicum $\times S$. lycopersicoides Dunal varied in subsequent years $(19.9 \%$ in the first year and $38 \%$ in the second). Chambonnet (2012) pointed out that two used genotypes of S. sisymbriifolium had an impact on tomato fruit set and embryo formation. Different specific cross combinations can also result in markedly different fruit setting rates. Kharkongar et al. (2013) found that crossing $S$. lycopersicum (cultivars MT3 and KA) with $S$. pimpinellifolium produced high fruit setting rates (35\% for MT3 and $32 \%$ for KA) but that crossing with $S$. peruvianum gave relatively low fruit setting rates (7\% for MT3 and $8 \%$ for KA), probably because of certain post-fertilization abnormalities.

Approximately $50 \%$ of the fruits produced after pollination with $S$. sisymbriifolium were parthenocarpic, containing only jelly-like tissue. Parthenocarpic fruits produced after crossing were also observed by Chambonnet (2012). Bal and Abak (2003) found enlarged ovules inside the fruits of only two crossed tomato cultivars, and also found that many of the obtained fruits were parthenocarpic. The results suggest that the lack of enlarged ovules in fruits can be attributed to very early embryo abortion or a parthenocarpic induction. Ho and Hewit (1994) noted that hybrid embryo abortion occurred 2-4 weeks after pollination when $S$. lycopersicum was crossed with $S$. pimpinellifolium. Numerous parthenocarpic fruits may form as a result of the parthenocarpy process induced by the presence of foreign pollen grains on the stigma. Stevens and Rick (1994) found that many parthenocarpic fruits were produced when tomatoes were crossed with $S$. pimpinellifolium.

In our study, post-fertilization barriers in the cross between tomatoes and $S$. sisymbriifolium occurred in the early stages of embryogenesis. Diploid, hybrid 

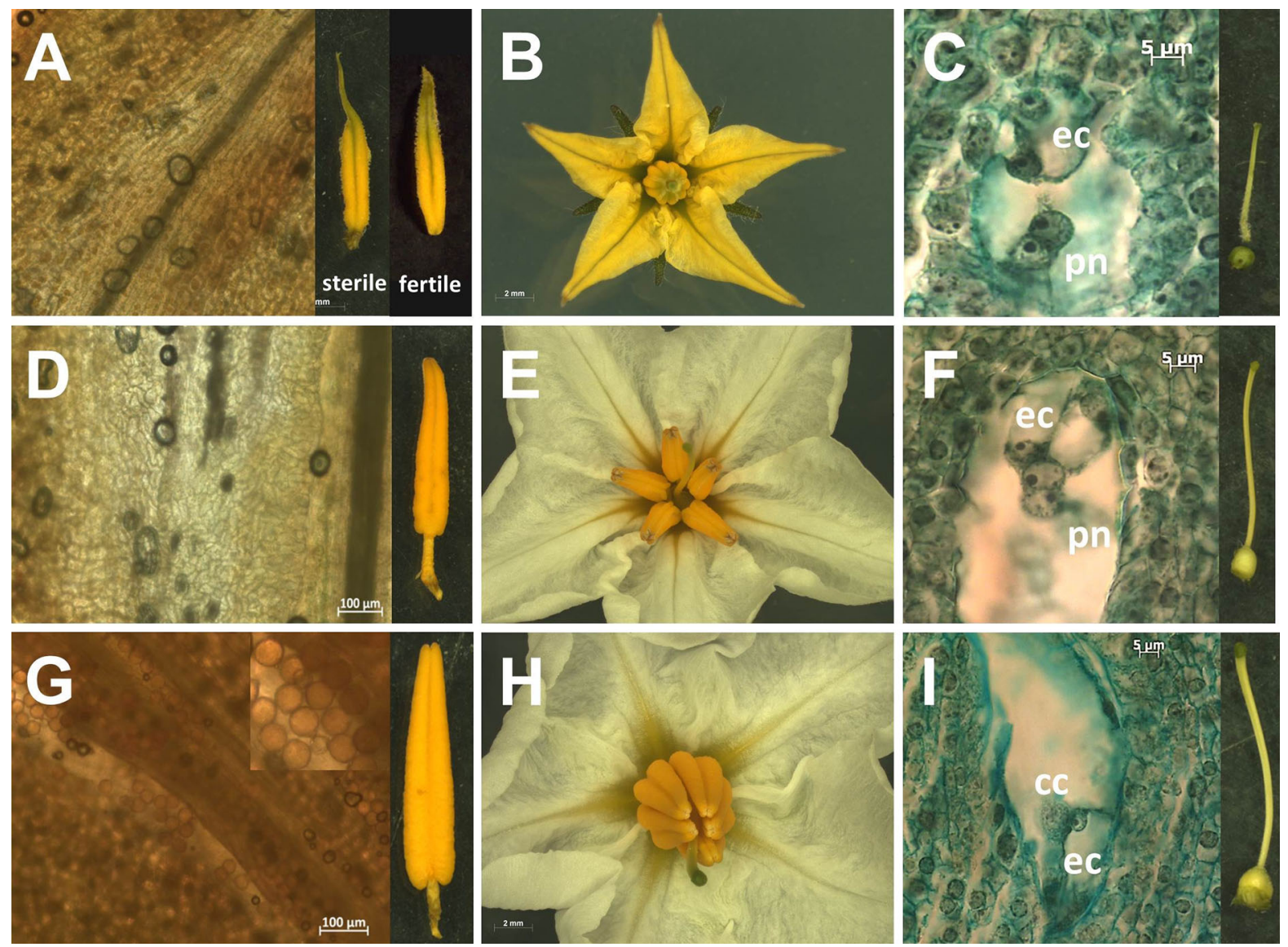

Fig. 10 Flower morphology of hybrid (e) and the parents: $S$. lycopersicum (b) and S. sisymbriifolium (h) plants. a Anther of male-sterile $S$. lycopersicum without pollen grains (stamen isolated from fertile tomato for comparison), c ovule of $S$. lycopersicum with embryo sac contained egg cell (ec), polar nuclei (pn) and one visible synergid (s), d "empty" anther of hybrid plant, $\mathbf{f}$ ovule of hybrid with fertile embryo sac, $\mathbf{g}$ anther of $S$. sisymbriifolium full of pollen grains, $\mathbf{i}$ ovules and well developed embryo sac of $S$. sisymbriifolium contained egg cell (ec) and central cell nuclei (cc)
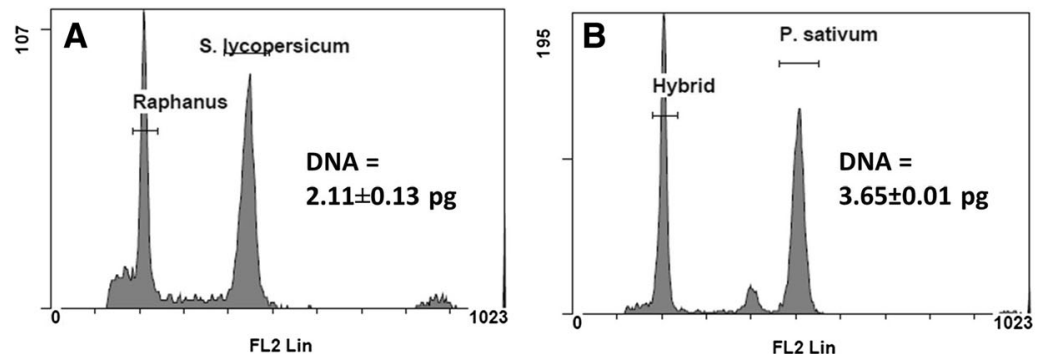

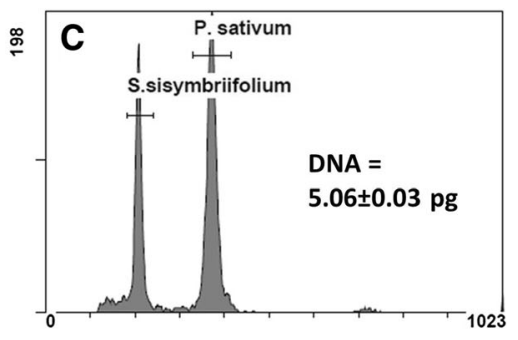

FL2 Lin

Fig. 11 Flow cytometry of DNA content: a S. lycopersicum, b hybrid, c S. sisymbriifolium

embryo formation was inhibited at the several-celled and globular stage because of developmental abnormalities. Simultaneously with embryos, endosperm which did not usually differ from the control material developed. Only in some ovules did the endosperm structure reveal developmental abnormalities as very dense cytoplasm of visibly flattened cells. Embryos usually of small size, often rapidly grew and consumed the endosperm available. The lack of compatible endosperm may have caused the embryos to collapse. 


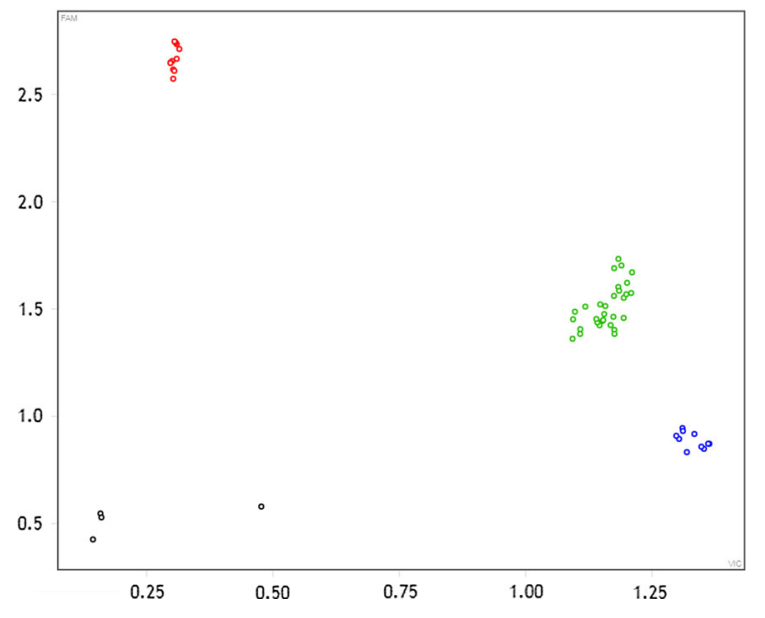

Fig. 12 Cluster plot of the KASP genotyping analysis using TOM2 SNP markers. Homozygote A (S. sisymbriifolium) was marked with FAM dye (red), and homozygote B (S. lycopersicum) was marked with VIC dye (blue). The hybrid $S$. lycopersicum $\times S$. sisymbriifolium (heterozygote $\mathrm{AB}$ ) was marked with both dyes (green). The black points marked "no target controls". (Colour figure online)

The work of Chambonnet (2012) showed a high rate of embryo formation (around 11\%) at the various stages. The author observed the presence of globular, heartshaped and torpedo embryos, even in the same fruit which is differ from our results. Chambonnet also highlighted significant differences in the size of induced embryos, which were much smaller than zygotic ones.

The inhibition of embryo development at the globular stage, was the main reason for adopting the embryo-rescue method. Culturing immature embryos is a well-known technique that allows the regeneration of hybrids in many cross combinations, such as Salix $\times$ Populus (Zenkteler et al. 2005; Bagniewska et al. 2011). Young embryos, at globular stage, require a medium enriched with specific additives such as coconut milk and casein hydrolysates or phytohormones, which could be a substitute for compatible endosperm (Sharma et al. 1996). In the present study we isolated globular embryos and nurse them on the tomato endosperm (unsuccessfully) or placed them directly on the media. Against the background of other authors who successfully cultured whole ovules with embryos (Bal and Abak 2003) or cultured the obtained embryos inside the nurse seed obtained after tomato self-pollination (Chambonnet 2012), our cultures of globular hybrid embryos revealed their various morphogenic responses. Regardless of the isolation time (14-35 dap), most embryos failed to develop on the selected media during the early days of culture (only 4 embryos developed to the cotyledonary stage) and a

Table 4 KASP genotyping analysis (using seven SNP markers) of four clones of S. lycopersicum 8450-10 (1-4), three clones of $S$. sisymbriifolium MM568-9 (1-3), and eight regenerants obtained after interspecific crossing (with reference Table 3 with SNP markers). (Colour Table online)

\begin{tabular}{|c|c|c|c|c|c|c|c|}
\hline Plant & TOM1 & TOM2 & TOM3 & TOM4 & TOM5 & TOM6 & TOM7 \\
\hline MM568-9-1 & B & A & A & B & A & B & $\mathrm{B}$ \\
\hline MM568-9-2 & B & A & A & B & A & B & B \\
\hline MM568-9-3 & B & A & A & B & A & B & B \\
\hline $8450-10-1$ & A & B & B & A & B & A & A \\
\hline $8450-10-2$ & A & B & B & A & B & A & $A$ \\
\hline $8450-10-3$ & A & B & B & A & B & A & A \\
\hline $8450-10-4$ & A & B & B & A & B & A & A \\
\hline 1 & $\mathrm{H}$ & $\mathrm{H}$ & $\mathrm{H}$ & $\mathrm{H}$ & $\mathrm{H}$ & $\mathrm{H}$ & $\mathrm{H}$ \\
\hline 2 & $\mathrm{H}$ & $\mathrm{H}$ & $\mathrm{H}$ & $\mathrm{H}$ & $\mathrm{H}$ & $\mathrm{H}$ & $\mathrm{H}$ \\
\hline 3 & $\mathrm{H}$ & $\mathrm{H}$ & $\mathrm{H}$ & $\mathrm{H}$ & $\mathrm{H}$ & $\mathrm{H}$ & $\mathrm{H}$ \\
\hline 4 & $\mathrm{H}$ & $\mathrm{H}$ & $\mathrm{H}$ & H & $\mathrm{H}$ & $\mathrm{H}$ & $\mathrm{H}$ \\
\hline 5 & $\mathrm{H}$ & $\mathrm{H}$ & $\mathrm{H}$ & $\mathrm{H}$ & $\mathrm{H}$ & $\mathrm{H}$ & $\mathrm{H}$ \\
\hline 6 & $\mathrm{H}$ & $\mathrm{H}$ & $\mathrm{H}$ & $\mathrm{H}$ & $\mathrm{H}$ & $\mathrm{H}$ & $\mathrm{H}$ \\
\hline 7 & $\mathrm{H}$ & $\mathrm{H}$ & $\mathrm{H}$ & $\mathrm{H}$ & $\mathrm{H}$ & $\mathrm{H}$ & $\mathrm{H}$ \\
\hline 8 & $\mathrm{H}$ & $\mathrm{H}$ & $\mathrm{H}$ & $\mathrm{H}$ & $\mathrm{H}$ & $\mathrm{H}$ & $\mathrm{H}$ \\
\hline
\end{tabular}


few embryos only oversized in vitro. However, a medium supplemented with zeatin or 2.4-D + zeatin stimulated callus formation in $>17 \%$ of the cultured embryos, especially in embryos isolated 20-22 dap. Chambonnet (2012) record a high death rate for embryos cultured in vitro. Over the 5 years of the experiments about 1000 embryos died shortly after transfer. In our work only a few embryos degenerated during culturing. These differences can be explained by the specific media composition used for the cultures. The author reported that after nursing heartshaped and torpedo embryos some plantlets developed rapidly. Bal and Abak (2003) obtained a few plantlets from the cultures of ovules with embryos. For the embryo-rescue method, besides the properly selected medium, the embryo developmental stage is a very important factor. The regeneration of plants from globular embryos is very difficult to carry out. Therefore, having only embryos at a globular stage, direct plant regeneration was unsuccessful. For example, the highest control tomato embryo germination rates were found for 28 and 32 day old cultured embryos, and the lowest control embryo germination rate was found for 20 day old embryos (Gebologlu et al. 2011).

As the embryos did not develop on the selected media, we focused on hybrid plant regeneration using embryo-callus cultures. Plants developed from cultured embryos via callus tissue have frequently been described. Cap et al. (1991) obtained hybrid plants from callus tissues from embryos of $S$. lycopersicum crossed with $S$. peruvianum. Using the same cross combination, Thomas and Pratt (1981) obtained calli from $12 \%$ of undeveloped tomato seeds cultured in vitro. In our work, morphogenic calli transferred to media without 2.4-D produced hybrid plantlets. The plantlets grew slowly, contrary to the results of $\mathrm{Bal}$ and Abak (2003) and Chambonnet (2012) who noticed the rapid growth of seedlings and plants. Some of the plantlets regenerated in our investigation only reached the rosette stage and they failed to develop roots. Overall from the 50 plantlets, only 10 plants were regenerated. The plants were originated from a callus proliferated from 10 individual embryos. From 10 obtained plants, 2 died a few weeks after acclimatization. Root tips of plants regenerated by $\mathrm{Bal}$ and Abak (2003) contained cells with diploid $(2 \mathrm{n}=24)$ or 25-26 number of chromosomes. Chambonnet (2012) noticed that the root tips of regenerated plants were a mixture of haploid $(n=12)$ and diploid cells. The authors suggest that the obtained embryos and plants had a haploid, gametic origin and the spontaneous chromosome doubling could have occurred during their development. In our research no haploid cells were observed in any of the analysed embryos. We did not check the ploidy status of the regenerants, although the 8 surviving plants were examined by DNA content and KASP analysis, which proved their hybrid nature.

The plants rescued from the in vitro cultures represented morphology similar to the S. sisymbriifolium male parent not to the maternal one. The presence of attributes of the wild parents has also been observed in other tomato cross combinations such as $S$. habrochaites or S. pimpinellifolium (Kalloo 1991). The morphological traits of $S$. lycopersicum $\times S$. sisymbriifolium hybrids which brought them closer to the paternal plants were bushy plant habit, shape of leaves, presence of prickles (much shorter than $S$. sisymbriifolium) on shoots and leaves, flowers with white corolla and similar shape of pistils and stamens. These plants grew significantly more slowly than $S$. sisymbriifolium, and the plant height and leaf length was lower. Embryological studies also revealed developmental abnormalities of the female and male gametophyte, probably due to post-zygotic incompatibility. The hybrids did not produce mature pollen and in $90 \%$ of cases produced unfertile embryo sacs. However $10 \%$ of the analysed embryo sacs were comprised of well developed egg and central cell nuclei. We later performed preliminary experimental cross pollination of hybrids with pollen grains collected from the parents. The pollination with tomato pollen was unsuccessful, however cross-pollination of hybrids with $S$. sisymbriifolium resulted at very low fruit set (fruits morphologically similar to $S$. sisymbriifolium). Interestingly, in some of the produced mature fruits, only globular embryos were present. These results indicated that hybrid progeny is partially female-fertile. The morphology of the obtained hybrids significantly differs from the regenerants obtained by Chambonnet (2012) which were similar to the $S$. lycopersicum material. Observations of pollen, embryos, plantlets and plants suggested a maternal, haploid origin of the regenerants, although the author notes that the transfer of induced embryos into young nurse seeds might cause uncontrolled disturbance, such as the possibility of plantlets 
development from nurse seeds instead of the induced embryo transferred into them (Chambonnet 2012). Our work demonstrated that it is possible to obtain hybrids of $S$. lycopersicum $\times S$. sisymbriifolium, phenotypically different from the maternal material, and with confirmed molecular status.

This is the first report describing the possibility of developing hybrid $S$. lycopersicum $\times S$. sisymbriifolium plants from immature embryos cultured in vitro via callus.

Acknowledgements The authors wish to thank the Rijk Zwaan Company (Fijnaart, The Netherlands) for providing $S$. lycopersicum and $S$. sisymbriifolium plants and for the opportunity to conduct this research. The authors wish to thank the anonymous reviewers for valuable help in improving this article.

Open Access This article is distributed under the terms of the Creative Commons Attribution 4.0 International License (http:// creativecommons.org/licenses/by/4.0/), which permits unrestricted use, distribution, and reproduction in any medium, provided you give appropriate credit to the original author(s) and the source, provide a link to the Creative Commons license, and indicate if changes were made.

\section{References}

Alconero R, Robinson RW, Dicklow B, Shail J (1988) Verticillium wilt resistance in eggplant, related Solanum species, and interspecific hybrids. HortScience 23:388-390

Bagniewska-Zadworna A, Zenkteler M, Zenkteler E, Wojciechowicz MK, Barakat A, Carlson JE (2011) A successful application of the embryo rescue technique as a model for studying crosses between Salix viminalis and Populus species. Aust J Bot 59:382-392. https:// doi.org/10.1071/BT10270

Bai Y, Lindhout P (2007) Domestication and breeding of tomatoes: what have we gained and what can we gain in the future? Ann Bot 100:1085-1094. https://doi.org/10.1093/ $\mathrm{aob} / \mathrm{mcm} 150$

Bal U, Abak K (2003) Attempts of haploidy induction in tomato (Lycopersicon esculentum Mill.) via gynogenesis I: pollination with Solanum sisymbriifolium Lam. pollen. Pak J Biol Sci 6(8):745-749. https://doi.org/10.3923/pjbs.2003. 745.749

Cap GB, Roberts PA, Thomason IJ, Murashige T (1991) Embryo culture of Lycopersicon esculentum $\times$ L. peruvianum. Hybrid genotypes possessing heat-stable resistance to Meloidogyne incognita. J Am Soc Hort Sci 116(6): 1082-1088

Chambonnet D (1996) Essaisd'haploidisation de la tomate. In: Report D' Activite 1995-1996 Station D'Amelioration Des Plantes Maraicheres D; Avignon-Montfavet, pp 84-85
Chambonnet D (2012) In situ induction of haploid gynogenesis in tomato. TGC report 62

Chetelat RT, Cisneros P, Stamova L, Rick CM (1997) A malefertile Lycopersicon esculentum $\times$ Solanum lycopersicoides hybrids enables direct backcrossing to tomato at the diploid level. Euphytica 95:99-108. https://doi.org/10. 1023/A:1002958030799

Collonnier U, Mulya K, Fock I, Mariska I, Servaes A, Vedel F, Siljak-Yakovlev S, Souvannavong V, Sihachakr D (2003) Somatic hybrids between Solanum melongena and $S$. sisymbriifolium as a useful source of resistance against bacterial and fungal wilts. Plant Sci 164:849-861. https:// doi.org/10.1016/S0168-9452(03)00075-X

D'arcy WG (1974) Solanum and its close relatives in Florida. Ann Mo Bot Gard 61:819-867

de Nettancourt D, Devreux M, Laneri U, Pacini E, Cresti M, Sarfatti G (1973) Ultrastructural aspects of unilateral interspecific incompatibility between Lycopersicum peruvianum and L. esculentum. Caryologia Suppl 25:207-217. https://doi.org/10.1080/00087114.1973.10797125

Dolezel J, Sgorbati S, Lucretti S (1992) Comparison of three DNA fluorochromes for flow cytometric estimation of nuclear DNA content in plants. Physiol Plant 85:625-631. https://doi.org/10.1111/j.1399-3054.1992.tb04764.x

Dolezel J, Greilhuber J, Lucretti S, Meister A, Lysak MA, Nardi L, Obermayer R (1998) Plant genome size estimation by flow cytometry: inter-laboratory comparison. Ann Bot 82(Suppl. A):17-26. https://doi.org/10.1006/anbo.1998. 0730

Erhardt W, Götz E, Bödeker N, Seybold S (2002) Zander Handwörterbuch der Pflanzennamen, 17th edn. Ulmer, Stuttgart

Fawzi NM, Habeeb HR (2016) Taxonomic studies on the wild species of genus Solanum L. in Egypt. Ann Agric Sci 61:165-173. https://doi.org/10.1016/j.aoas.2016.10.003

Galbraith D, Harkins K, Maddox J, Ayres N, Sharma D, Firoozabady E (1983) Rapid flow cytometric analysis of the cell cycle in intact plant tissues. Science 220:1049-1051. https:// doi.org/10.1126/science.220.4601.1049

Gebologlu N, Bozmaz S, Aydin M, Cakmak P (2011) The role of growth regulators, embryo age and genotypes on immature embryo germination and rapid generation advancement in tomato (Lycopersicon esculentum Mill.). Afr J Biotechnol 10(24):4895-4900. https://doi.org/10.5897/AJB10.2275

Ho LC, Hewit JD (1994) Fruit development. In: Atherton JG, Rudich J (eds) The tomato crop, a scientific basis for improvement. Springer, New York, pp 201-239. https:// doi.org/10.1007/978-94-009-3137-4

https://npgsweb.ars-grin.gov/gringlobal/taxonomydetail. aspx?992101521. Accessed 10 Apr 2018

http://www.lgcgroup.com/kasp/\#.WhvZdlXiaUk. Accessed 08 Sept 2018

Kalloo G (1991) Genetic improvement of tomato. Springer, New York

Kharkongar HP, Khanna VK, Tyagi W, Rai M, Meetei NT (2013) Wide hybridization and embryo-rescue for crop improvement in Solanum. Agrotechnology 11:004. https:// doi.org/10.4172/2168-9881.S11-004

Knapp S (2002) Tobacco to tomatoes: a phylogenetic perspective on fruit diversity in the Solanaceae. J Exp Bot 53:2001-2022. https://doi.org/10.1093/jxb/erf068 
Melchers G, Sacristan MD, Holder AA (1978) Somatic hybrid plants of potato and tomato regenerated from fused protoplasts. Carlsberg Res Commun 43(4):203-218. https:// doi.org/10.1007/BF02906548

Miller JC, Tanksley SD (1990) RFLP analysis of phylogenetic relationships and genetic variation in the genus Lycopersicon. Theor Appl Genet 80:437-448. https://doi.org/10. 1007/BF00226743

Murashige T, Skoog F (1962) A revised medium for rapid growth and bioassays tobacco tissue culture. Physiol Plant 15:473-497. https://doi.org/10.1111/j.1399-3054.1962. tb08052.x

O'Connell MA, Hanson MR (1986) Regeneration of somatic hybrid plants formed between Lycopersicon esculentum and Solanum rickii. Theor Appl Genet 72:59-65

Peralta IE, Knapp S, Spooner DM (2005) New species of wild tomatoes (Solanum section Lycopersicon: Solanaceae) from Northern Peru. Syst Bot 30:424-434. https://doi.org/ 10.1600/0363644054223657

Safni I, Cleenwerck I, De Vos P, Fegan M, Sly L, Kappler U (2014) Polyphasic taxonomic revision of the Ralstonia solanacearum species complex: proposal to emend the descriptions of Ralstonia solanacearum and Ralstonia syzygii and reclassify current $R$. syzygii strains as Ralstonia syzygii subsp. Syzygii subsp.nov., R. solanacearum phylotype IV strains as Ralstonia syzygii subsp. indonesiensis subsp. nov., banana blood disease bacterium strains as Ralstonia syzygii subsp. celebesensis subsp. nov. and $R$. solanacearum phylotype I and III strains as Ralstonia pseudosolanacearum sp. nov. Int J Syst Evol Microbiol 64:3087-3103. https://doi.org/10.1099/ijs.0.066712-0

Sharma DR, Kaur R, Kumar K (1996) Embryo rescue in plants-a review. Euphytica 89:325-337. https://doi.org/ 10.1007/BF00022289

Sikora EJ, Gazaway S (2009) Wilt diseases of tomato. Alabama A\&M and Auburn Universities. Alabama Cooperative Extension System. ANR-0797:1-6
Smith PG (1944) Embryo culture of a tomato species hybrid. Proc Am Soc Hort Sci 44:413-416

Sohrab SS, Bhattacharya PS, Rana D, Kamal MA, Pande MK (2015) Development of interspecific Solanum lycopersicum and screening for Tospovirus resistance. Saudi J Biol Sci 22:730-738. https://doi.org/10.1016/j.sjbs.2014.11. 009

solgenomics.net. Accessed 06 Sept 2018

Stevens MA, Rick CM (1994) Genetics and breeding in the tomato crop. In: Atherton JG, Rudich J (eds) A scientific basis for improvement. Chapman and Hall, London, pp 35-109. https://doi.org/10.1007/978-94-009-3137-4

Thomas BR, Pratt D (1981) Efficient hybridization between Lycopersicon esculentum and L. peruvianum via embryo callus. Theor Appl Genet 59:215-219. https://doi. org/10.1007/BF00265495

Walter JM (1967) Heredity resistance to disease in tomato. Annu Rev 5:131-160. https://doi.org/10.1146/annurev.py. 05.090167.001023

Weese TL, Bohs L (2007) A three-gene phylogeny of the genus Solanum (Solanaceae). Syst Bot 32(2):445-463. https:// doi.org/10.1600/036364407781179671

Zenkteler M, Wojciechowicz M, Bagniewska-Zadworna A, Zenkteler E, Jeżowski S (2005) Intergeneric crossability studies on obtaining hybrids between Salix viminalis and four Populus species. Trees 19(6):638-643. https://doi. org/10.1007/s00468-005-0427-2

Ziebur NK, Brink RA (1951) The stimulative effect of Horderum endosperms on the growth of immature plant embryos in vitro. Am J Bot 38(4):253-256. https://doi.org/ 10.1002/j.1537-2197.1951.tb14820.x

Publisher's Note Springer Nature remains neutral with regard to jurisdictional claims in published maps and institutional affiliations. 